\title{
Non-communicable diseases and climate change: linked global emergencies
}

In the Annual University College London-Lancet Global Health Lecture in April, 2019, we called for non-communicable diseases (NCDs) to be regarded as a global emergency and we compared the spread of NCDs to climate change, a global emergency of unprecedented proportion. This is not hyperbole-there is ample reason for that claim. NCDs present an overwhelming and widespread threat to populations globally and cause more than $70 \%$ of global health deaths. ${ }^{1}$ Worldwide, there are more than 1.1 billion people who have high blood pressure, almost 800000 people die from suicide, 425 million adults have diabetes, and about $40 \%$ of adults are overweight or obese..$^{2-5}$ All these numbers are expected to rise. WHO has said that without dramatic new intervention the Sustainable Development Goal (SDG) target to reduce premature NCD mortality by a third by 2030 will fail. ${ }^{6}$

The parallels between NCDs and climate change go beyond statistics to causal factors. Both are preventable. Both are caused to a large degree by human behaviour. And both require a multisectoral response. Yet neither are prioritised by responsible global and national policy makers. Infamously, the USA walked away from the Paris Climate Change Accord in 2017 and signatories have made unsatisfactory progress to date. ${ }^{7}$ It is similarly easy to point to weak leadership and action on NCDs. The WHO Framework Convention on Tobacco Control, one of the most widely adopted UN treaties, lacks ratification by several governments, including the USA, and its impact is marred by industry interference and variable implementation. ${ }^{8}$ WHO's NCD Progress Monitor, which charts the implementation of recommended national strategies for the prevention of NCDs, shows that progress is insufficient. ${ }^{9}$ There is no global health institution dedicated to addressing NCDs. Indeed, WHO downgraded the leadership position responsible for NCDs in Geneva in the past year and other global health institutions have backed away from earlier signalled openness to 
work on NCDs. No official public donor has a programme dedicated to addressing NCDs in poor countries.

While NCDs are not the only global problem that merits greater attention and resources, it is an example of a syndemic - a synergy of epidemics that co-occur in time and place, interact to produce complex sequelae, and share common underlying social drivers. ${ }^{10,11}$ However, while the syndemic of HIV/AIDS (for which the term syndemic was coined) received $24 \%$ of global donor assistance for health in 2017, NCDs, which claim far more lives, receive only $2 \%$ of global health donor funding, leaving most low-income countries to tackle the problem on their own. ${ }^{12}$ Why is the response not commensurate to the threats posed by NCDs?

Multiple cognitive and political challenges prevent us from responding to obvious threats that are large-scale, complex, and seemingly far off. Economists identify one such challenge as temporal discounting or time inconsistency. Humans often choose instant gratification and short-term pay-offs over long-term considerations. We also, often erroneously, assume the future will look basically like the present. These behaviours amplify many NCD risks that are invisible and non-linear. Another cognitive distortion is defensive attribution: we put responsibility on those who are harmed while not feeling any responsibility ourselves. People still refer to lifestyle diseases even though there are broad socioeconomic and environmental causes of NCDs, and entire industries exist to profit from products or activities that increase NCD risks. ${ }^{13}$

On the public policy side, with politicians perpetually focused on the immediacy of the next election, under the influence of highly paid lobbyists and targeted campaign contributions, and influenced by strategic disinformation, companies are left free to market low-cost, highprofit products that adversely impact the environment and human health. 
Where does this leave us? Like climate change, NCDs are a global disaster, and like climate change, there are solutions to NCDs. We have evidence of what works and we know where we need to make changes. For example, eliminating the half a trillion US dollars spent each year on subsidising fossil fuels and multibillion dollar annual subsidies to industrialised agriculture, using health taxes alongside other health promotion tools to influence the behaviours and incentives of individuals and communities, and investing our research and health-care dollars to understand and respond to the wide determinants and consequences of NCDs. ${ }^{14,15}$ As is true of climate change, the question is not can we afford to do what is needed to reduce NCDs, but can we afford not to? The answer is, we cannot-the need for action is urgent and the consequences of failure are massive.

\section{*Rachel Nugent, Edward Fottrell}

RTI International, Seattle, WA 98104, USA (RN); and Centre for Global Non-Communicable Diseases, Institute for Global Health, University College London, London, UK (EF) rnugent@rti.org

We declare no competing interests. This Comment is based on the University College London-Lancet Annual Global Health Lecture given by Rachel Nugent and discussed by Edward Fottrell in London, UK, on April 29, 2019.

1 NCD Countdown 2030 collaborators. NCD Countdown 2030: worldwide trends in noncommunicable disease mortality and progress towards Sustainable Development Goal target 3.4. Lancet 2018; 392: 1072-88.

2 NCD Risk Factor Collaboration (NCD-RisC). Worldwide trends in blood pressure from 1975 to 2015: a pooled analysis of 1479 population-based measurement studies with $19 \cdot 1$ million participants. Lancet 2017; 389: 37-55. 
3 WHO. Global health estimates 2016: disease burden by cause, age, sex, by country and by region, 2000-2016. Geneva: World Health Organization, 2018.

4 International Diabetes Federation. IDF diabetes atlas, 8th edition. Brussels, Belgium: International Diabetes Federation, 2017.

5 The GBD 2015 Obesity Collaborators. Health effects of overweight and obesity in 195 countries over 25 years. N Engl J M 2017; 377: 13-27.

6 WHO. Time to deliver: report of the WHO Independent High-level Commission on Noncommunicable Diseases. Geneva: World Health Organization, 2018.

7 Climate Action Tracker. Some progress since Paris, but not enough, as governments amble towards $3^{\circ} \mathrm{C}$ of warming. December, 2018.

https://climateactiontracker.org/documents/507/CAT_2018-12-

11_Briefing_WarmingProjectionsGlobalUpdate_Dec2018.pdf (accessed July 29, 2019).

8 Chung-Hall J, Craig L, Gravely S, Sansone N, Fong GT. Impact of the WHO FCTC over the first decade: a global evidence review prepared for the Impact Assessment Expert Group. Tobacco Control 2019; 28 (suppl 2): 119-28.

9 WHO. Noncommunicable Diseases Progress Monitor 2017. Geneva: World Health Organization, 2017.

10 Mendenhall E, Kohrt BA, Norris SA, Ndetei D, Prabhakaran D. Non-communicable disease syndemics: poverty, depression, and diabetes among low-income populations. Lancet 2017; 389: 951-63.

11 Swinburn BA, Kraak VI, Allender S, et al. The Global Syndemic of Obesity, Undernutrition, and Climate Change: The Lancet Commission report. Lancet 2019; 393: 791-846. 
12 Institute for Health Metrics and Evaluation. Financing global health 2017: funding universal health coverage and unfinished HIV/AIDS agenda. Seattle, WA: Institute for Health Metrics and Evaluation, 2018.

13 Nugent R, Bertram MY, Jan S, et al. Investing in non-communicable disease prevention and management to advance the Sustainable Development Goals. Lancet 2018; 391: 2029-35.

14 Yates R. Recycling fuel subsidies as health subsidies. Bull World Health Organ 2014; 92: 547-547A.

15 The Task Force on Fiscal Policy for Health. Health taxes to save lives: employing effective excise taxes on tobacco, alcohol, and sugary beverages: Bloomberg Philanthropies, 2019. 